\title{
Phonological awareness and learning to read in Afrikaans: The role of working memory
}

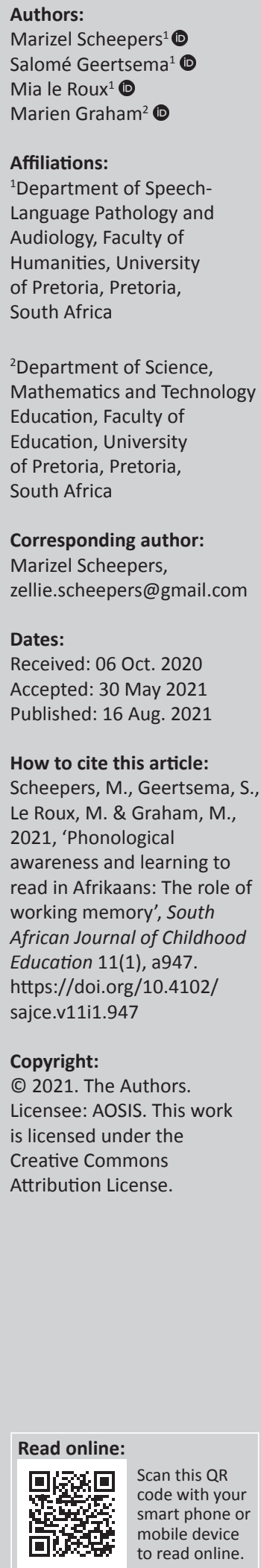

Background: Phonological awareness (PA) skills and working memory (WM) are universally regarded as crucial precursors to skilled reading. The orthography of the language being read influences the ease with which a child learns to read. Research has been undertaken on reading in languages with an opaque orthography. Research on the role of PA and WM in Afrikaans with its transparent orthography is limited.

Aim: The study investigated and described the role of WM in the acquisition of PA and ultimately reading in Afrikaans.

Setting: The research study was conducted in private schools with Afrikaans as the language of learning and teaching (LoLT) in Grade 2.

Method: A descriptive research design with correlational components was applied.

Results: Phonetic decoding was employed more than eidetic decoding. Word reading skills developed rapidly and exceeded the expectations in the first two quarters of the year. Participants who read the comprehension test fluently scored higher on the questions than those who did not read fluently. The correlation between WM and reading comprehension was not statistically significant. The statistically significant correlation between WM and word reading seems to be present in both transparent and opaque orthographies. The statistically significant correlation between PA and word reading was not found in other transparent orthographies. The correlation between phonemic awareness (PhA) and word reading is the same in other orthographies.

Conclusion: The statistically significant correlation between WM and word reading indicates that WM supports reading development as the ability to hold information in memory supports phoneme-grapheme associations.

Keywords: Afrikaans; beginning readers; decoding strategies; phonemic awareness; phonological awareness; transparent orthography; working memory.

\section{Introduction}

The development of proficient reading skills is a fundamental objective of school (Dessemontet \& De Chambrier 2015). The ability to read and subsequently to learn through reading is important in the academic success of learners (Finlayson 2017). Attaining a high level of phonological awareness (PA) skills enables a child to acquire reading skills more easily as these skills interact with and facilitate the development of vocabulary and word consciousness both on recognition and encoding level (Finlayson 2017). Learning to read requires the sequential decoding of the graphemes into their spoken form and temporarily storing the various forms in the exact order until the last grapheme has been decoded (Dessemontet \& De Chambrier 2015). Adequate phoneme-grapheme association knowledge secures the connection in memory (Li et al. 2016). Phoneme-grapheme correspondence improves the quality of lexical representations in the memory ( $\mathrm{Li}$ et al. 2016). Phonemic awareness (PhA) skills, primarily blending and segmentation are required to connect the pronunciation and spelling of a word and to preserve these words in the memory (Ehri 2014). Research suggests that working memory (WM) is one of the most important predictors of children's reading abilities and later academic success (Giofrè, Donolato \& Mammarella 2018; Toffalini et al. 2019). Research on the role of PA skills and WM in Afrikaans is limited. Furthermore, to the researchers' knowledge, no comparable research project involving Afrikaans as a transparent orthography has been conducted. A more robust understanding of PA and the role of WM in learning to read in Afrikaans will contribute to support programmes for young readers.

One of the main skills acknowledged as essential in early literacy development is PA (Korat et al. 2017; Li et al. 2019). Phonological awareness, a metalinguistic skill, entails the awareness and manipulation 
of phonological segments of a spoken language (Lynch 2016). A child's sensitivity to the sound structure of a language is illustrated through the level of PA skills displayed (Li et al. 2019). Phonological awareness development starts early with the less sophisticated skill of alliteration and/or rhyme detection, which may support how a child understands the way in which words are divided into sound units (Read \& Regan 2018). The development of PA continues to syllable awareness, a pre-requisite for phoneme awareness and ultimately reading skills to develop (Mehta et al. 2018). The next level of PA development concerns onset and rime (Korat et al. 2017; Lynch 2016; Zuriyatiaslina et al. 2018). Onset-rime awareness is the ability to recognise that a solitary syllable consists of two units. The onset is any initial phoneme before the vowel, whilst the rime is the vowel and remaining phonemes of the syllable (Zuriyatiaslina et al. 2018). The development of the ability to manipulate even smaller sections of a word continues until the child is able to manipulate single phonemes (Ehri 2014).

The final most sophisticated sub-skill of PA to develop is PhA (Ehri 2014; Lynch 2016). Phonemic awareness entails the ability to distinguish the smallest sound unit of oral language (a phoneme) that makes a difference to the meaning of a word (Lynch 2016). This sub-skill of PA entails the understanding that spoken words can be divided into individual initial, medial and final phonemes and that different words can be formed by combining these phonemes (Ehri 2014). Segmenting words into phonemes as well as blending, deleting and substituting phonemes comes about as a result of PhA skills (Lynch 2016). Phonemic awareness skills enable learners to segment words into phonemes as well as to blend, delete and substitute phonemes when reading (Lynch 2016). Manipulating phonemes on this level by making connections between phonemes in spoken words and graphemes in written words is essential when learning to read (Korat et al. 2017). In this way, phoneme-grapheme association is established, thus connecting speech to print (Korat et al. 2017). The ability to link phonemes to graphemes is called phonics. The developmental progression from less sophisticated PA skills, providing scaffolding for the more sophisticated PhA skills and to phonic skills ultimately is necessary for successful reading acquisition (Lervåg \& Aukrust 2010). Figure 1 visually depicts the development of PA and PhA skills.

The development of decoding and reading comprehension skills are essential components of becoming a skilful reader (Schaars, Segers \& Verhoeven 2019). When decoding unfamiliar words, beginner readers are typically instructed to identify the shape and orientation of graphemes and associate them with the correct phonemes (Pham \& Hasson 2014). A child is instructed to read by applying specific phonetic decoding strategies when reading unfamiliar words (Ehri 2014; Stark 2011). Sight words stored in the memory are retrieved and read by using eidetic decoding strategies (Ehri 2014; Stark 2011). Once proficient decoding skills have been attained, reading comprehension skills start to develop gradually (Schaars et al. 2019). A child steadily learns to read longer and more complex orthographic structures containing

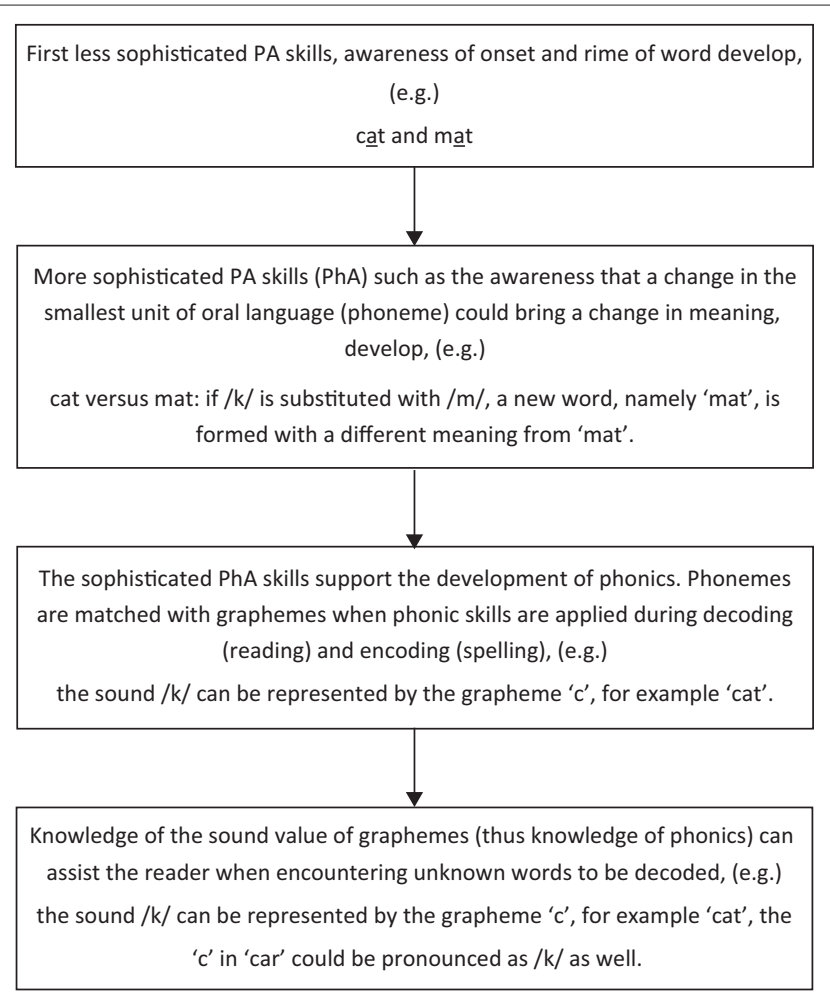

Source: Lervåg, A. \& Aukrust, V.G., 2010, 'Vocabulary knowledge is a critical determinant of the difference in reading comprehension growth between first and second language learners', Journal of Child Psychology and Psychiatry 51(5), 612-620.

$\mathrm{PA}$, phonological awareness; PhA, phonemic awareness.

FIGURE 1: The progression of applying specific phonetic decoding skills.

consonant clusters and multi-syllabic words once the fundamental decoding skills have been developed (Schaars, Segers \& Verhoeven 2017).

The orthography of a language has a significant effect on the development of reading skills (Rakhlin et al. 2019). A child learns to read sight words through orthographic mapping (Ehri 2014;Stark2011). When a child makes use of orthographic mapping, phonetic decoding strategies are not used anymore for familiar words as the words are read immediately from memory (Ehri 2014; Li et al. 2016). Phonological awareness and $\mathrm{PhA}$ skills, automatic phoneme-grapheme association and accurate decoding of words by identifying the sounds phoneme by phoneme, all facilitate orthographic mapping (Ehri 2014). Readers apply orthographic mapping in second and third grades (Rakhlin et al. 2019). As beginner readers become more fluent, words are spontaneously read by means of orthographic processing, which allows more effective visual storage of familiar and unfamiliar words into longterm memory (Pham \& Hasson 2014). As a result, the connections between the phoneme, grapheme and semantic components become stronger (Schaars et al. 2017).

Alphabetic orthographies - or writing systems - are all created on the principles of phoneme-grapheme association (Vibulpatanavong \& Evans 2019). The orthography of a language is described as being either transparent or opaque (De Sousa, Greenop \& Jessica 2011). Opaque orthographies present with inconsistent and unpredictable phoneme- 
grapheme association rules, and graphemes may represent a number of different phonemes, for example, the English writing system consists of several ways to pronounce the same grapheme, for example, the a in: start /a:/, call / o:/, cat $/ æ /$, care /eə/ and another /ə/ (De Sousa et al. 2011). In transparent orthographies, such as Afrikaans, the phonemegrapheme association rules are reliable, and graphemes mostly symbolise only one phoneme (De Sousa et al. 2011; Tibi \& Kirby 2018). Afrikaans is considered a language with a shallow orthography as the grapheme ' $a$ ' in Afrikaans (kat) is a straightforward grapheme-phoneme association compared to one-to-many correspondence of the same grapheme in English (car, make, swan, ball, dare). As the phoneme-grapheme association is more straightforward in transparent orthographies, decoding skills as well as reading fluency and accuracy develop more easily (Tibi \& Kirby 2018; Vibulpatanavong \& Evans 2019). The development of these skills might be less challenging because of the relatively lighter cognitive load. The young reader does not have to keep all the different permutations of the sounds that a grapheme might represent in mind (Vibulpatanavong \& Evans 2019).

An effective foundation for reading fluency is orthographic knowledge of words as it provides a mnemonic device that helps children to keep the pronunciations in their memory (Korat et al. 2017). Beginner readers must be able to memorise arbitrary correspondences between abstract visual shapes (representations of phonemes and words) and verbal codes (Toffalini et al. 2019). This visualphonological association is an example of cross-modal binding (Toffalini et al. 2019). Cross-modal binding is the integration of information from different sensory sources to form complex, integrated representations that can be retained in memory (Toffalini et al. 2019).

As children work out complex tasks, they need to remember some information whilst processing other information (Linnegar, Condy \& McKinney 2014). Working memory is a multicomponent system responsible for temporarily storing a limited amount of auditory and visual information whilst this information is being manipulated (Blankenship et al. 2015). Working memory is used in higher cognitive skills such as reading and is a central component of the executive function that allows children to process information and regulate attention in addition to helping them achieve cognitive-linguistic goals (Blankenship et al. 2015; Linnegar et al. 2014). Children need to remember some information whilst processing other information as they work out complex tasks (Linnegar et al. 2014). The subsystems of WM are the central executive, the two slave systems - phonological loop and visuospatial sketchpad - and the episodic buffer (Kellogg et al. 2016).

The central executive prioritises incoming information, retrieves information from long-term memory and controls selective attention across sensory storage areas (Argyropoulos et al. 2017). The WM components are controlled by the central executive (Kellogg et al. 2016). The phonological loop is responsible for temporary storing and maintaining verbal information in a phonological form (Afshar et al. 2017; Argyropoulos et al. 2017; Kellogg et al. 2016). Phonological awareness is normally associated with the phonological loop (De Weerdt, Desoete \& Roeyers 2013). A number of previous studies point to the phonological loop as the principal system affected in children with reading difficulties. This is founded on the difficulties they experience in processing and storing linguistic information (Pham \& Hasson 2014). Children are required to link the visual form of a word and the corresponding pronunciation of the word to identify words successfully during reading tasks (Wang et al. 2015).

The visuospatial sketchpad maintains and processes information with a visual or spatial element, for example, forms of graphemes (Afshar et al. 2017; Argyropoulos et al. 2017). This component is involved in reading tasks such as the maintenance of a stable representation of the page and its design. Furthermore, it enables correct eye movement from the end of one line to the beginning of the next (Baddeley 2012). The episodic buffer, a multi-dimensional buffer, allows the different components of WM to interact (Baddeley, Allen \& Hitch 2011). The episodic buffer integrates visual and verbal information and connects these integrated episodes to multi-dimensional illustrations in the long-term memory (Baddeley 2012). Working memory can therefore be understood to promote reading success as it supports the formulation of words as well as the capacity to maintain these words for comprehension (Blankenship et al. 2015).

The development of proficient reading skills is a fundamental objective of school (Dessemontet \& De Chambrier 2015). The ability to read and subsequently to learn through reading becomes an essential part of how academically successful learners are (Finlayson 2017). The process of reading includes the activation of orthographic, phonological and semantic structures of words (Finlayson 2017). As PA and WM have constantly emerged in various reports as essential precursors to skilled reading, it is crucial to examine the development and roles of these competencies. Many research projects have been undertaken on reading in a language with an opaque orthography, such as English. However, existing research on the role of WM and PA skills in Afrikaans is limited. Moreover, to the knowledge of the researcher, no similar research projects involving Afrikaans as a transparent orthography have been conducted. The present study aimed for a robust understanding of PA and the role of WM in learning to read in Afrikaans as a transparent language. The aim was to explore and describe the role of WM in the acquisition of PA skills and ultimately in reading Afrikaans. Subordinate objectives were to describe the Grade 2 Afrikaans L1 participants' level of decoding, oral reading rate, level of reading comprehension, WM, PA and PhA skills and, finally, to correlate the latter aspects with the early decoding skills of the participants.

The following research question is posed: What role does WM play in the acquisition of PA skills and, ultimately, in 
learning to read Afrikaans, a language with a transparent orthography?

\section{Method}

\section{Research design}

A cross-sectional descriptive study with correlational components was conducted. A cross-sectional design assesses a single group of participants at one specific point in time. A descriptive design identifies characteristics of observed aspects. The correlational design was used to determine whether a relationship exists between variables and to describe the relationship (Christensen, Johnson \& Turner 2015).

\section{Study population and sampling strategy Participation selection procedures}

The participants and schools were selected based on their willingness to participate as well as convenience sampling (Christensen et al. 2015). The research study included 35 Afrikaans (L1) male and female participants selected from five private schools in Gauteng, South Africa, with Afrikaans as a language of learning and teaching (LoLT). A total of 30 or more participants had to be selected for the statistical analysis using Statistical Package for Social Sciences (SPSS) (version 26) to be applicable. The participants were assessed during the first and second quarters of the academic year. The average age of the participants was 7 years and 7 months with a standard deviation (SD) of 0.446 . The researchers endeavoured to match the participants and private schools as closely as possible to control external influences. The selected private schools and participants represented similar socioeconomic backgrounds. The similar background was implicit because of the circumstance that private schools generally serve middle- to high-income households. Moreover, the private schools used the same LoLT and curriculum, and school fees are also within the same range (Languille 2016).

\section{Exclusion and inclusion criteria}

The participants selected for the research study were between the ages of 7 and 8 years 11 months. This identified range is the required age for a child to be in Grade 2 . Additionally, basic decoding skills are expected to be mastered in Grade 2 (Rakhlin et al. 2019). Participants who had repeated Grade R or Grade 1 and who were older than 9 years were excluded from the research study. The home language of the participants as well as their language of instruction from Grade R onward is Afrikaans. Participants with reported speech, language or neurological disorders such as attention-deficit hyperactivity disorder were excluded. In cases where the parent or guardian or teacher appeared to be unaware that a potential participant was exhibiting the characteristics of a possible disorder, the participant was excluded and referred for a formal assessment.

\section{Setting}

The participants were assessed in quiet rooms with limited auditory and visual distractions.

\section{Data collection and analysis procedures Data collection}

The participants were assessed using the assessment tools described in the section on materials and apparatus. The data were captured on an Excel spreadsheet, and a numeric code was assigned to the individual data of each participant to ensure confidentiality. Prior to the statistical analysis, the data entered on the spreadsheet were verified thoroughly.

\section{Data collection material and apparatus}

The administered assessment tools were standardised. It must be noted, although, that not all the assessment tools were standardised for the Afrikaans population. However, the translated versions have been employed successfully for a substantive period in South African practice and were accepted as appropriate for the present study. The assessment tools were utilised to support the aim of the research study. The assessment tools used for obtaining the desired data were:

- Phonological Awareness Test-Second Edition: Normative Update (PAT-2) (Robertson \& Salter 2018) measured awareness of spoken syllables and phonemes.

- Test of Auditory Processing Skills (TAPS-3) (Martin \& Brownell 2005) assessed PA and WM skills. The following subtests were used to assess PA and PhA, the segmentation and blending. The number -, word - and sentence memory and number memory forward and number memory reversed assessed the WM skills.

- One-minute reading test (OMRT) (Transvaal Education Department 1987) assessed the reading speed of sight words and word reading fluency. If the participants made use of phonetic decoding skills to read the word, the word was not considered to be part of the sight word vocabulary of the participant.

- Stark-Griffin dyslexia determination test (DDT) (Stark 2011) investigated phonetic and eidetic (sight word) decoding skills. The test is generally used to diagnose specific learning disorder (developmental dyslexia) by dyslexia specialists. For this investigation, only reading accuracy regarding decoding was observed.

- Illinois test of psycholinguistic abilities (ITPA) (Kirk, McCarthy \& Kirk 1982) assessed the visuospatial sketchpad.

- A prescribed comprehension test from the Curriculum Assessment Policy Statement (CAPS) (Department of Basic Education 2019) was read aloud by all the participants and ten comprehension questions answered.

\section{Reliability and validity}

Possible elements of error within each individual measurement were kept as small as possible. The following factors were taken into account to ensure that identical or 
nearby results were obtained (Christensen et al. 2015): environment factors, participant changes and research factors.

Face and content validity were accounted for to ensure thoroughness and comprehensiveness of the research and results obtained (Christensen et al. 2015). The desired data were obtained through normal and standardised assessments recommended and used by other professionals. The assessment tools were purposefully selected to correspond to the aim of the research study.

\section{Data analysis}

The decoding skills of the participants were described and classified as phonetic or eidetic or a combination where both decoding skills were applied. The results attained from the OMRT and DDT were analysed and compared. Reading accuracy was described using the outcomes of the DDT. The speed and sight word vocabulary of the participants were described according to the OMRT results. Phonological awareness, PhA and WM skills were described in a detailed manner to determine whether the skills of the participants support their ability to read successfully. The TAPS-3 (assessing PA, PhA and WM) results were analysed and correlated with the decoding skills of the participants. A statistician correlated the results using the SPSS (version 26). The data were analysed using the Spearman correlations (Field 2018). The purpose was to determine the degree of association between PA, PhA, WM and decoding skills.

\section{Ethical considerations}

Ethical considerations were taken into account to ensure the welfare and dignity of the participants. Ethical clearance was obtained from the Research and Ethics Committee of the Faculty of Humanities, University of Pretoria. Written permission was obtained from the principals of the private schools, allowing the research to be conducted on the schools' premises in quiet rooms with minimal visual and auditory distractions. The researchers obtained informed written consent from the parents or caregivers of each participant. Each participant provided child assent by selecting the correct illustration on the assent form (pointing to a happy or sad face). The participants also provided written assent by writing their names on the assent form. The confidentiality of the participants was ensured by the use of numeric codes. The following ethical principles governed the research process and authentic decisions made throughout the research study: beneficence, non-maleficence, honesty and confidentiality.

\section{Results and discussion}

\section{Objective 1: Describing the early decoding skills of Grade 2 Afrikaans (L1) learners using the results of the dyslexia determination test (Stark 2011)}

The participants decoded $33.60 \%$ of the words phonetically and $25.20 \%$ of the words through eidetic decoding. This outcome signifies that phonetic strategies were still applied more often than eidetic strategies at this early stage of Grade 2. Astudy conducted with Vietnamese participants confirmed that word reading skills are mastered initially and quickly in transparent orthographies (Pham \& Snow 2020). These results are consistent with those obtained by Suggate et al. (2014) who reported on German, which also has a transparent orthography. These authors reported that readers of German have an advantage in word reading skills compared to readers of English, which has an opaque orthography. In the initial phase of learning to read in Greek, which also has a transparent orthography, the participants similarly used phonetic decoding (Sarris 2020). A plausible explanation is that children learning to read a transparent orthography depend more on the phonological than the morphological structure of the language (Sarris 2020). Phoneme-grapheme associations are fundamental processes to assist beginning readers to build up orthographic representations in their mental lexicons, which will ultimately enable easy and quick eidetic decoding (Schmalz, Marinus \& Castles 2013). The participants in the current study decoded more words phonetically as the orthographic representations in their mental lexicons are still being constructed (Schmalz et al. 2013). The latter view is supported by Rakhlin et al. (2019) who reported that all basic decoding skills are mastered by the end of Grade 2. Orthographic mapping for both transparent and opaque orthographies is activated through frequent reading as basic decoding skills develop, which will result in more complete word spelling being stored in the mental lexicons of the reader, thus building the sight word vocabulary (Li et al. 2016; Rakhlin et al. 2019). The participants in the current study decoded $58.80 \%$ words correctly and $22.63 \%$ words incorrectly, whilst $18.57 \%$ of the test stimuli were not read. The phoneme-grapheme associations were still accurate for most of the test stimuli although $22.63 \%$ of words were decoded incorrectly. The incorrectly decoded words were the longer stimuli, consisting of three to four syllables. These are words to which the participants also would have had little to no reading exposure. Steacy et al. (2020) concurred that longer words are understandably more challenging to read initially and require more exposure for mastery than shorter words. Pham and Snow's (2020) study of the transparent Vietnamese orthography confirmed that children learning to read languages with transparent orthographies master word reading skills quickly. Beginning readers of pointed Hebrew, which is considered a transparent orthography, also develop word reading accuracy fairly easily based on the direct phoneme-grapheme associations (Nevo et al. 2020). These findings provide a possible reason why most words were decoded correctly by the participants in the study in hand. Another plausible explanation is that when phoneme-grapheme associations are developed in transparent orthographies, reading acquisition becomes largely a process of orthographic learning and acquiring unitised word reading (Rakhlin et al. 2019). It is therefore reasonable to assume that the Afrikaans Grade 2 participants were, during the first two quarters of the academic year, still in the beginning phase of orthographic learning as basic decoding skills were being mastered. The Afrikaans Grade 2 
participants' eidetic decoding skills should improve with reading experience as more complete word spellings will be stored in the metal lexicons of readers (Rakhlin et al. 2019; Schaars et al. 2017). This seems to be the case for other transparent orthographies, where the early decoding skills seem to develop along similar lines to in Afrikaans. What makes reading development a challenging task nonetheless is the acquisition of words consisting of larger units, in order to ultimately become a fluent reader (Steacy et al. 2020).

\section{Objective 2: Describing the oral reading rate of the Grade 2 Afrikaans (L1) learners using the results of the one-minute reading test (Transvaal Education Department 1987)}

The participants read on average 50.94 words per minute during the OMRT. The average reading age was 7 years 9 months. The SD for the OMRT was 21.57. As mentioned in the section on participant selection procedures, the average age for the assessed participants was 7 years and 7 months, with an SD of 0.446. Children are expected to read between 33 and 68 sight words per minute by the end of Grade 2 (Transvaal Education Department 1987). These results indicate that the participants had already achieved or even exceeded the expectations in the first and second quarters of the academic year. The maximum score of 99 words was achieved by one participant $(n=1 ; 2.86 \%)$ and the minimum of 11 words by two $(n=2 ; 5.71 \%)$ participants. Although 13 $(n=13 ; 37.14 \%)$ participants read fewer sight words than anticipated for their age, only six $(n=6 ; 17.14 \%)$ participants read fewer than 33 words, the basal for Grade 2 participants. These results support the finding (Objective 1) that word reading skills develop rapidly in transparent orthographies (Pham \& Snow 2020; Suggate et al. 2014). The findings are also supported by the fact that the participants were assessed in the beginning of the academic year.

In English, which has an opaque orthography, a low reading rate is often confused with low reading accuracy (Rakhlin et al. 2019). In transparent orthographies with consistent phoneme-grapheme associations, a low reading rate manifests itself as a reading rate disorder, characterised by accurate, but slow and effortful reading including failure to attain sight word reading (Rakhlin et al. 2019). The statement of Rakhlin et al. (2019) regarding Russian with its transparent orthography is based on the predisposition of readers to use orthographically incorrect but phonological reasonable spelling. Similar results were obtained in the present study. As was to be expected, the participants with a low reading rate read the comprehension test (text reading fluency) more slowly than participants with a higher reading rate. In most cases, the words were still read accurately although the participants read slowly with more effort. There were, however, five $(n=5 ; 14.26 \%)$ participants who not only displayed a low reading rate but also decoded many of the words incorrectly. These five participants read fewer words than expected for their age and less than the expected basal for Grade 2 children during the OMRT. Furthermore, the five $(n=5 ; 14.26 \%)$ also obtained poor scores of $9,15,16,17$ and
18 , respectively, for the segmenting subtest. The scores for the blending subtest were poor for three $(n=3 ; 8.57 \%)$ of the five $(n=5 ; 14.26 \%)$ participants, with scores of 12,15 and 19. The latter is worth noting as the PhA skills, segmenting and blending are strongly predictive of adequate reading skills. It is possible that the decoding skills of these participants are not as developed as those of the other participants. The sight word vocabulary of readers expands as their orthographic mapping skills improve, which will improve the oral reading rate of the readers (Ehri 2014). Likewise, this improved orthographic mapping and expanded sight word vocabulary can be an explanation as to why some participants read more sight words per minute and subsequently displayed a higher reading rate. A final explanation offered for the present overall higher reading rate of these participants compared to the expected outcomes set by the normative data of the OMRT is the transparent orthography of Afrikaans. It can safely be stated that the average oral reading rate of these Grade 2 Afrikaans participants exceeded the expectations even in the first two quarters of the academic year. The rapid development of word reading skills in other transparent orthographies seems to be in agreement with the findings for Afrikaans.

\section{Objective 3: A description of the reading comprehension skills of Afrikaans (L1) readers in Grade 2}

The mean score for the reading comprehension test was 7.29 out of 10. The SD for the comprehension test was 1.90. The maximum score of 10 was obtained by three $(n=3 ; 8.57 \%)$ participants and the minimum score of two by only one $(n=1 ; 2.86 \%)$ participant. It was subsequently noted that participants who read the comprehension test fluently, quickly and accurately with proper expression (Swain, Leader-Janssen \& Conley 2013) obtained a higher score on the questions. Twenty participants $(n=20 ; 57.14 \%)$ who read the comprehension test fluently scored seven or higher out of 10 . A score of six was obtained by two $(n=2 ; 5.71 \%)$ participants who read the comprehension test fluently and only one $(n=1$; $2.86 \%$ ) participant, also fluent, scored three. These results are consistent with results from other studies conducted in transparent orthographies (Kim, Park \& Wagner 2014; Nevo et al. 2020). The general conclusion is that, as readers develop fluency, cognitive resources can be focussed on comprehension of the text and not on decoding words (Kim et al. 2014; Nevo et al. 2020). Three $(n=3 ; 8.57 \%)$ of the five $(n=5 ; 14.26 \%)$ participants with a low reading rate (mentioned in Objective 2) scored six on the comprehension test, which is higher than expected. The individual differences in word reading skill, which is a foundational component of reading comprehension (Kim et al. 2014), are a possible explanation. The text reading fluency of the participants made a greater contribution to their reading comprehension performance, however, than word reading fluency. This conclusion was made as participants who did not read the anticipated number of words for their age during the OMRT did not necessarily also underperform during the comprehension test. Eighteen $(n=18 ; 51.71 \%)$ of the 22 participants $(n=22 ; 62.86 \%)$ 
who read the expected number of words during the OMRT for their age equivalent scored seven or higher in the comprehension test. However, only three $(n=3 ; 8.57 \%)$ participants who underperformed in the OMRT obtained five or lower for the comprehension test. Ten $(n=10 ; 28.57 \%)$ participants who read fewer words during the OMRT compared to their age equivalent scored six or higher on the comprehension test. A plausible explanation is that the relationship of word reading fluency to reading comprehension weakens from the initial to the later phases of learning to read (Kim et al. 2014). The decline is because of the development of reading skills. This was reported by Kim et al. (2014) after research conducted with participants learning to read Korean, which has a transparent orthography. A similar study by Kim and Wagner (2015) found this outcome also for English, which has an opaque orthography. Text reading fluency becomes independently related to reading comprehension. Once a certain level of word reading proficiency has developed, text reading fluency becomes an additional influence on reading comprehension together with word reading fluency and listening comprehension (Kim \& Wagner 2015). This can serve as a plausible reason for text reading fluency being more predictive of the reading comprehension performance of the participants than their word reading fluency. Peng et al. (2018) provided another explanation. From their meta-analysis, these authors reported that it was less challenging for participants to read sentences than to read lists of words with no semantic context. The semantic context enables participants to read the sentences faster and more fluently. However, research in Finnish, Greek and Korean, all with transparent orthographies, indicated that listening comprehension becomes a stronger prediction of reading comprehension over time (Argyropoulos et al. 2017; Kim et al. 2014). The reading comprehension skills of the participants are in agreement with those found by other studies conducted in languages with transparent orthographies. The research generally indicates that as fluency develops, cognitive resources can be focussed on comprehension of the text rather than on decoding words. The weakening of the link between word reading fluency and reading comprehension skills seems to happen also in languages with opaque orthographies.

\section{Objective 4: A description of working memory, phonological awareness and phonemic awareness skills of the Afrikaans (L1) Grade 2 learners}

In line with the penultimate objective, Table 1 and Table 2 and the subsequent narratives present the data describing the WM skills of the participants.

\section{Number memory forward and reversed}

Number memory forward is a measurement of the phonological loop's capacity whilst number memory reversed, where the data have to be manipulated, measures the central executive (Afshar et al. 2017; Giofrè et al. 2016). Number memory forward, a 'passive' task, involves a limited amount of execute control (Giofrè et al. 2016). An 'active' task comprises double requests and/or control for irrelevant data (Giofrè et al. 2016). Number memory reversed is a task considered to be distributed between passive and active. The number memory reversed task was more challenging as it required more executive control and manipulation. It is therefore predictable that the participants would find it difficult to remember and manipulate information simultaneously. The central executive system includes higher-level cognitive skills including attention, planning and inhibition (Afshar et al. 2017). Thus, we propose that these higher cognitive skills are still developing in Afrikaans Grade 2 children.

\section{Word memory}

The outcomes in Table 1 for the word memory subtest indicate that the participants have a word memory span of four to five words on average. Shorter words, for example, car, are generally recalled more easily than longer words, for example, banana (Saint-Aubin et al. 2020). This is true for French, with an opaque orthography (Saint-Aubin et al. 2020) and also true for the present study in a transparent orthography.

\section{Sentence memory}

The mean score of the sentence memory subtest indicates that the participants were on average able to recall a sentence with $8-10$ words. It is possible that the semantic connotations between words in sentences facilitate the process of remembering and recalling the sentence. The results are supported by Peng et al.'s (2018) meta-analysis reporting that participants find it less challenging to recall a sentence with 8-10 words compared to recalling single words. In Objective 3, similar finding was reported regarding the semantic context making the task less challenging for the participants.

\section{Visual-spatial memory}

The participants were able to recall on average four to five visual-spatial blocks, according to the mean score for this

TABLE 1: Results of working memory skills $(n=35)$.

\begin{tabular}{lccccc}
\hline WM skills & Mean & Median & SD & $\begin{array}{c}\text { Minimum } \\
\text { score }\end{array}$ & $\begin{array}{c}\text { Maximum } \\
\text { score }\end{array}$ \\
\hline Number memory forward & 7.51 & 7 & 1.46 & 4 & 10 \\
Number memory reversed & 3.31 & 3 & 1.05 & 2 & 6 \\
Word memory & 8.51 & 8 & 1.77 & 5 & 11 \\
Sentence memory & 10.41 & 10 & 2.38 & 7 & 16 \\
Visual-spatial memory & 11.91 & 12 & 2.54 & 6 & 17 \\
\hline
\end{tabular}

WM, working memory; SD, standard deviation.

TABLE 2: Results of phonological awareness and phonemic awareness skills $(n=35)$.

\begin{tabular}{lccccc}
\hline PA and PhA skills & Mean & Median & SD & Minimum score & Maximum score \\
\hline Rhyme discrimination & 8.51 & 9 & 1.62 & 4 & 10 \\
Rhyme production & 5.86 & 6 & 2.94 & 0 & 10 \\
Syllabification & 7.11 & 8 & 2.40 & 2 & 10 \\
$\begin{array}{l}\text { Phonological } \\
\text { segmentation }\end{array}$ & 25.11 & 26 & 6.32 & 9 & 34 \\
Phonological blending & 27.06 & 28 & 5.18 & 12 & 34 \\
\hline
\end{tabular}

PA, phonological awareness; PhA, phonemic awareness; SD, standard deviation. 
subtest. The visual-spatial memory skills of the participants were not an indication of their decoding or reading comprehension skills. The participants who obtained the mean score or a higher score on the visual-spatial subtest did not all read the expected number of words for their age in the OMRT and vice versa. Ten participants $(n=10 ; 28.57 \%)$ scored lower than the mean for the visual-spatial subtest although they read the estimated numbers of words for their age during the OMRT. These findings are consistent with those from a study in English, which has an opaque orthography, where it was reported that the visual-spatial sketchpad delivers no significant contribution to reading fluency (Pham \& Hasson 2014). A probable explanation is that as reading fluency requires responding under a timed condition, processing speed may contribute more to reading fluency than WM (Pham \& Hasson 2014). This is in contrast, however, with the findings of De Weerdt et al. (2013) regarding German, a language with a transparent orthography, that children with reading difficulties experience problems in all components of WM.

Higher cognitive skills of the central executive that facilitate more executive control and manipulation are still developing in Afrikaans Grade 2 children. The Afrikaans Grade 2 participants recalled shorter words more easily than longer words, which are consistent with other findings from languages with opaque orthographies. It is seemingly true for both orthographies that the semantic context makes it less challenging to recall sentences than words. When considering other transparent orthographies, the influence of the visualspatial sketchpad on reading fluency seems to differ in comparison with Afrikaans. However, the results in this study of the visual-spatial sketchpad having no significant contribution to reading fluency are in agreement with findings from other opaque orthographies.

\section{Rhyming}

The rhyme discrimination subtest was less challenging than the rhyme production subtest. A study involving Englishspeaking South African participants (Manten et al. 2020) also indicated that the production of rhyme words was challenging. Rhyme awareness did not make a significant contribution to the development of reading skills in the transparent orthography of Finnish (Suortti \& Lipponen 2016). Children typically show awareness of syllables and rhymes, before they display sensitivity to phonemes (Duncan 2018). Our study therefore suggests that although rhyming contributes to the development of $\mathrm{PhA}$ and ultimately phoneme-grapheme association, the individual roles of rhyme discrimination and production may be different for Afrikaans.

\section{Syllabification}

Syllable awareness is one of the earlier PA skills to develop (Mehta et al. 2018). Children reading languages with transparent orthographies generally have sufficient awareness of syllables (Güldenoğlu 2017). However, 12 participants $(n=12 ; 34.29 \%)$ scored below the mean score of 7.11. Both Güldenoğlu (2017) and Müller, Richter and Karageorgos (2020) reported that syllable awareness has a more significant impact on decoding words in a transparent orthography than in opaque orthographies. Thirteen participants $(n=13 ; 37.14 \%)$ who obtained the mean score or higher read the expected number of words per minute during the OMRT. However, six participants $(n=6 ; 17.14 \%)$ read the expected number of words during the OMRT but obtained a score of six or lower in the syllabification subtest. Furthermore, 10 participants $(n=10 ; 28.57 \%)$ obtained the mean score or higher for the syllabification subtest but read fewer words than expected during the OMRT. Finally, only six participants $(n=6 ; 17.14 \%)$ obtained less than the mean for the syllabification subtest and did not read the expected number of words during the OMRT. The present study's results are in contrast with those from Güldenoğlu (2017) and Müller et al. (2020) as the syllable awareness of the participants did not have a significant impact on the word decoding skills of the Afrikaans participants.

\section{Phonological segmentation and blending}

The estimated expected scores for Grade 2 children in the segmentation subtest are between 24 and 30 and for the blending subtest between 16 and 21 (Martin \& Brownell 2005). Thirteen ( $n=13 ; 37.14 \%)$ participants obtained a score below the estimated score for the segmentation subtest and three $(n=3 ; 8.57 \%)$ participants for the blending subtest. Although the results on both subtests exceeded normative data overall, the results indicated that the perception and blending of different phonemes were less challenging for the participants. Research in English has also reflected that phonological blending was more developed and less challenging than segmentation skills (Le Roux et al. 2017; Suortti \& Lipponen 2016). Participants who scored the mean or above on the segmentation subtest read more words correctly during the OMRT. However, 12 ( $n=12 ; 34.26 \%)$ participants who read the anticipated number of words per minute did not obtained the mean score for the blending subtest. It can be concluded that blending is less challenging than segmenting in both transparent and opaque orthographies (Le Roux et al. 2017; Suortti \& Lipponen 2016). In the current study, segmenting skills seemed to facilitate word reading development to a greater extent than blending skills. The latter argument is made as participants who obtained the mean score or higher for the segmenting subtest read the expected number of words or more during the OMRT, but this was not true for the blending subtest.

When compared to findings from other languages with transparent orthographies, rhyming awareness did also not contribute significantly to the acquisition of reading skills in Afrikaans. The influence of syllable awareness on the reading skills of participants differs from that reported for other transparent orthographies. Finally, the results of the blending subtest, reflective of less challenge than the segmenting subtest, seem to be in agreement with findings from opaque orthographies. 


\section{Objective 5: Correlating working memory, phonological awareness and phonemic awareness skills with the early decoding skills of the Grade 2 learners}

The concluding objective entailed the statistical correlations of the WM, PA and PhA skills with early decoding skills to ultimately explore the role of WM in the development of PA skills. The correlations may depict possible WM relationships with reading in a language with transparent orthography, such as Afrikaans (see Table 3).

The correlations between WM and the OMRT and DDT were both of fair strength with $r=0.366$ and 0.350 , respectively. However, the correlation coefficient between WM and the reading comprehension test was not statistically significant. These results are consistent with those reported by Arrington et al. (2014), who stated that WM is a cognitive correlate for reading but not necessarily the strongest predictor of reading skills in English with its opaque orthography. The relation of WM to reading skills is therefore ostensibly the same in both orthographies. A plausible justification for this study's findings could be that WM demonstrated a weaker relation to text reading fluency than word list reading fluency (Peng et al. 2018). Moreover, an untimed reading comprehension passage may involve less WM skills than timed tasks as the time limit constitutes a greater cognitive load (Peng et al. 2018). Finally, the correlation of fair strength can be explained by Schaefer and Kotzé (2019), who pointed out that children will find it difficult to associate a phoneme with its corresponding grapheme if items cannot be held in memory (Schaefer \& Kotzé 2019) (see Table 4).

The correlation coefficients were moderate in strength for correlations between PA skills and both the OMRT ( $r=0.707)$ and DDT (0.752). However, the correlation between PA and reading comprehension $(r=0.567)$ was only fair in strength. The moderately strong correlations, albeit statistically significant, are in contrast with research reporting that PA does not predict reading skills for the transparent orthographies of Greek, Finnish and Dutch (Landerl et al. 2019; Suortti \& Lipponen 2016). A possible explanation may

TABLE 3: Working memory skills correlated with early reading skills.

\begin{tabular}{lccc}
\hline Spearman correlation & $\begin{array}{c}\text { Correlation } \\
\text { coefficient }\end{array}$ & $p$ & $\begin{array}{c}\text { Number of } \\
\text { participants }\end{array}$ \\
\hline WM skills correlated with OMRT & 0.336 & 0.049 & 35 \\
WM skills correlated with DDT & 0.350 & 0.040 & 35 \\
$\begin{array}{l}\text { WM skills correlated with reading } \\
\text { comprehension }\end{array}$ & 0.220 & 0.204 & 35 \\
\hline
\end{tabular}

DDT, Dyslexia Determination Test; WM, working memory; OMRT, One-Minute Reading Test.

TABLE 4: Phonological awareness skills correlated with reading skills.

\begin{tabular}{lccc}
\hline Spearman correlation & $\begin{array}{c}\text { Correlation } \\
\text { coefficient }\end{array}$ & $p$ & $\begin{array}{c}\text { Number of } \\
\text { participants }\end{array}$ \\
\hline PA skills correlated with OMRT & 0.707 & 0.000 & 35 \\
PA skills correlated with DDT & 0.752 & 0.000 & 35 \\
$\begin{array}{l}\text { PA skills correlated with reading } \\
\text { comprehension }\end{array}$ & 0.567 & 0.000 & 35 \\
\hline
\end{tabular}

DDT, Dyslexia Determination Test; OMRT, One-Minute Reading Test; PA, phonological awareness. be that PA seems to be more significant during the earlier phases of reading development when phoneme-grapheme correspondences are still being learned (Tibi \& Kirby 2018). Once children have mastered phoneme-grapheme association, the relation of PA to reading skills may be less powerful as phoneme-grapheme association is acquired more rapidly in transparent orthographies (Pfost et al. 2019). In German, which has a transparent orthography, reading accuracy is acquired earlier than in the opaque orthography of English (Pfost et al. 2019). The importance of early phonology increases with the complexity of the orthography (Al Dahhan, Kirby \& Munoz 2016; Landerl et al. 2019). However, PA may be equally important for children struggling to develop adequate reading skills in a transparent orthography (Pfost et al. 2019). In summary, PA may rather act as a co-requisite than a prerequisite skill for developing typical reading skills in languages with a transparent orthography such as Afrikaans (Landerl et al. 2019; Suortti \& Lipponen 2016) (see Table 5).

The correlation coefficients were moderate in strength for both the OMRT $(r=0.653)$ and DDT $(r=0.763)$ correlated with the PhA skills of the participants. The correlation between PhA skills and the performance of the participants in the reading comprehension test was only fair in strength $(r=0.542)$. The correlations are statistically significant as the $p$-value is $<0.05$. The moderate correlations between PhA skills and the OMRT and DTT are in agreement with the results of Lynch's (2016) meta-analysis. This author reports that phoneme segmentation and blending skills are important constructs to develop optimal reading skills, especially in opaque orthographies. Furthermore, in Greek - a language with a transparent orthography - the early performance of children on $\mathrm{PhA}$ was related to their later reading skills (Pittas 2018). The moderately strong correlation found in the current study may be explained by the transparent orthography of Afrikaans. Transparent orthographies have a weaker association with PhA because of the consistency between phonemes and graphemes (Pittas 2018). However, some researchers propose that deficits in PhA skills may be a consequence of reading difficulties rather than a cause (Rakhlin et al. 2019). The average performance of participants on the segmenting and blending subtests was above the estimated scores for the age levels of the participants (as mentioned in Objective 4). Segmenting and blending skills may provide children learning to read in a transparent orthography such as Afrikaans with greater sensitivity to the phonological structures of a word, ultimately supporting their reading skills (Suortti \& Lipponen 2016).

TABLE 5: Phonemic awareness skills correlated with the early reading skills.

\begin{tabular}{lccc}
\hline Spearman correlation & $\begin{array}{c}\text { Correlation } \\
\text { coefficient }\end{array}$ & $p$ & $\begin{array}{c}\text { Number of } \\
\text { participants }\end{array}$ \\
\hline PhA skills correlated with OMRT & 0.653 & 0.000 & 35 \\
PhA skills correlated with DDT & 0.763 & 0.000 & 35 \\
$\begin{array}{l}\text { PhA skills correlated with reading } \\
\text { comprehension }\end{array}$ & 0.542 & 0.00 & 35 \\
\hline
\end{tabular}

DDT, Dyslexia Determination Test; OMRT, One-Minute Reading Test; PhA, phonemic awareness. 
The relation of WM to reading skills seems to be the same for both transparent and opaque orthographies. The moderately strong correlations found between PA skills and word reading skills seem to differ from findings in other transparent orthographies. The moderately strong correlation between PhA skills and reading skills, in contrast, is consistent with findings from other transparent orthographies.

\section{Conclusion}

Phonetic decoding was the primary decoding strategy used by the participants. The rapidly growing word skills of the participants support their oral reading rate, and these outcomes seem to be in agreement with those for other transparent orthographies. Likewise, the reading comprehension skills of the Afrikaans participants are similar to those found in other transparent orthographies. The capacity of the phonological loop is greater than that of the executive control system. As such, the semantic context supports the recall of information. Another interesting aspect is that the relation of WM to word reading and reading fluency skills was non-significant. This finding differs from other results reported for the transparent and opaque orthographies. Moreover, the rhyming skills of the participants had no relation to their reading skills, and this seems to be in agreement with the results from studies on other orthographies. However, when considering other transparent orthographies such as Turkish and German, the influence of syllable awareness on word reading skills seems to differ from that found for Afrikaans. Moreover, the blending and segmenting skills of participants exceeded the norms according to the participants' age range.

Finally, the statistically fairly significant correlation between WM and word reading skills is seemingly the same for both types of orthographies. The correlations between PA and reading skills of the participants were statistically significant but differ from those found for other transparent orthographies such as Greek, Dutch and Finnish. The statistically moderately significant relation of $\mathrm{PhA}$ to the word reading skills of the Afrikaans participants was similar to that found for other transparent orthographies.

\section{Limitations and strengths}

The research study was conducted on a small but statistically adequate sample of 35 participants. The assessment of the WM, PA, PhA and early reading skills was completed during the first two quarters of the academic year. The study included only participants in Grade 2 in private schools. However, in spite of these limitations, the study provided valuable new data on the WM, PA, PhA and early reading skills of Afrikaans learners in Grade 2 and subsequently on the transparent orthography of this language.

\section{Recommendations}

The PA, PhA, WM and reading skills of Grade 2 children should be assessed in the third and last quarters of the academic year to allow time for the expected skills to develop fully. The PA, PhA, WM and early reading skills could also be assessed at the beginning of Grade $\mathrm{R}$ to identify difficulties experienced by individuals and to allow early intervention. The development of successful reading skills can be supported by early identification and intervention.

\section{Acknowledgements}

The researchers wish to acknowledge and thank the private schools' principals, Grade 2 teachers, participants and parents or caregivers of participants.

\section{Competing interests}

The authors declare that no personal or financial relationships had an inappropriate influence in the writing of the article.

\section{Authors' contributions}

M.S. carried out the assessments and wrote the manuscript with support and guidance from S.G. and M.L.R.

\section{Funding information}

The authors received no financial support for the research study or for the publication of this article.

\section{Data availability}

The data of this study are available upon request from the authors, M.S., S.G. and M.L.R., in accordance with ethical considerations.

\section{Disclaimer}

The views and opinions expressed in this article are those of the authors and do not necessarily reflect the official policy or position of any affiliated agency of the authors.

\section{References}

Afshar, M.R., Ghorbani, A., Rashedi, V. \& Jalilevand, N., 2017, 'Working memory in Persian-speaking children with speech sound disorders and normal speech development', International Journal of Pediatric Otorhinolaryngology 101, 117-122. https://doi.org/10.1016/j.ijporl.2017.07.034

Al Dahhan, N.Z., Kirby, J.R. \& Munoz, D.P., 2016, 'Understanding reading and reading difficulties through naming speed tasks: Bridging the gaps among neuroscience, cognition, and education', AERA Open 2(4), 1-15. https://doi.org/10.1177/ 2332858416675346

Argyropoulos, V., Masoura, E., Tsiakalo, T.K., Nikolaraizi, M. \& Lappa, C., 2017, 'Verbal working memory and reading abilities among students with visual impairment', Research in Developmental Disabilities 64, 87-95. https://doi.org/10.1016/j. ridd.2017.03.010

Arrington, C.N., Kulesz, P.A., Francis, D.J., Fletcher, J.M. \& Barnes, M.A., 2014, 'The contribution of attentional control and working memory to reading comprehension and decoding', Scientific Studies of Reading 18(5), 325-346.

Baddeley, A.D., 2012, 'Working memory: Theories, models, and controversies', Annua Review of Psychology 63, 1-29. https://doi.org/10.1146/annurev-psych-120710 100422

Baddeley, A.D., Allen, R.J. \& Hitch, G.J., 2011, 'Binding in visual working memory: The role of the episodic buffer', Neuropsychologia 49(6), 1393-1400. https://doi. org/10.1016/j.neuropsychologia.2010.12.043

Blankenship, T.L., O'Neil, M., Ross, A. \& Bell, M.A., 2015, 'Working memory and recollection contribute to academic achievement', Learning and Individual Differences 43, 164-169. https://doi.org/10.1016/j.lindif.2015.08.020

Christensen, L.B., Johnson, R.B. \& Turner, L.A., 2015, Research methods, design, and analysis, 12th edn., Pearson Education Limited, Harlow. 
Department of Basic Education, 2019, Curriculum assessment policy statement: Afrikaans home language Grade 2 - Book 1, Department of Basic Education, Pretoria.

De Sousa, D., Greenop, K. \& Jessica, F., 2011, 'Cross-language transfer of spelling strategies in English and Afrikaans grade 3 children', International Journal of Bilingual Education and Bilingualism 14(1), 49-67. https://doi.org/10.1080/13670051003657959

Dessemontet, R.S. \& De Chambrier, A.-F., 2015, 'The role of phonological awareness and letter-sound knowledge in the reading development of children with intellectual disabilities', Research in Development Disabilities 41(42), 1-12. https://doi.org/10.1016/j.ridd.2015.04.001

De Weerdt, F., Desoete, A. \& Roeyers, H., 2013, 'Working memory in children with reading disabilites and/or mathematical disabilities', Journal of Learning Disabilities 46(5), 461-472. https://doi.org/10.1177/0022219412455238

Duncan, L.G., 2018, 'Language and reading: The role of morpheme and phoneme awareness', Current Developmental Disorders Reports 5(4), 226-234. https://doi. org/10.1007/s40474-018-0153-2

Ehri, L.C., 2014, 'Orthographic mapping in the acquisition of sight word reading, spelling memory, and vocabulary learning', Scientific Studies of Reading 18(1), 5-21. https://doi.org/10.1080/10888438.2013.819356

Field, A., 2018, Discovering statistics using IBM SPSS statistics, 5th edn., Sage, Thousand Oaks, CA.

Finlayson, C.J., 2017, 'Rhythm detection and production: Relations with phonological awareness skill at school-entry', Masters thesis, Brock University St. Catharines, viewed 28 February 2020, from http://hdl.handle.net/10464/12904.

Giofrè, D., Donolato, E. \& Mammarella, I.C., 2018, 'The differential role of verbal and visuospatial working memory in mathematics and reading', Trends in Neuroscience and Education 12, 1-6. https://doi.org/10.1016/j.tine.2018.07.001

Giofrè, D., Stoppa, E., Ferioli, P., Pezzuti, L. \& Cornoldi, C., 2016, 'Forward and backward digit span difficulties in children with specific learning disorder', Journal of Clinical and Experimental Neuropsychology 38(4), 478-486. https://doi.org/10 .1080/13803395.2015.1125454

Güldenoğlu, B., 2017, 'The effects of syllable-awareness skills on the word-reading performances of students reading a transparent orthography', International Electronic Journal of Elementary Education 8(3), 425-442.

Kellogg, R.T., Turner, C.E., Whiteford, A.P. \& Mertens, A., 2016, 'The role of working memory in planning and generating written sentences', Journal of Written Research 7(3), 397-416. https://doi.org/10.17239/jowr-2016.07.03.04

Kim, Y.S.G. \& Wagner, R. K., 2015, 'Text (oral) reading fluency as a construct in reading development: An investigation of its mediating role for children from grades 1 to 4', Scientific Studies of Reading, 19(3), 224-242. https://doi.org/10.1080/108884 38.2015.1007375

Kim, Y.S.G., Park, C.H. \& Wagner, R.K., 2014, "Is oral/text reading a "bridge" to reading comprehension?', Reading and Writing 27(1), 79-99. https://doi.org/10.1080/10 88mprehension?', Reading

Kirk, S., McCarthy, J. \& Kirk, W., 1982, Illinois test of psycholinguisitc abilites: The examiner's manual, University of Illinois Press, Urbana, IL.

Korat, O., Gitait, A., Deitcher, D.B. \& Mevarech, Z., 2017, 'Early literacy programme as support for immigrant children and as transfer to early numeracy', Early Child Development and Care 187(3-4), 672-689. https://doi.org/10.1080/03004430.20 16.1273221

Landerl, K., Freudenthaler, H.H., Heene, M., De Jong, P.F., Desrochers, A., Manolitsis, G. et al., 2019, 'Phonological awareness and rapid automatized naming as longitudinal predictors of reading in five alphabetic orthographies with varyin degrees of consistency', Scientific Studies of Reading 23(3), 220-234. https://doi. org/10.1080/10888438.2018.1510936

Languille, S., 2016, 'Affordable' private schools in South Afica: Affordable for whom?' Oxford Review of Education 42(5), 528-542. https://doi.org/10.1080/03054985.2 016.1220086

Lervåg, A. \& Aukrust, V.G., 2010, 'Vocabulary knowledge is a critical determinant of the difference in reading comprehension growth between first and second language learners', Journal of Child Psychology and Psychiatry 51(5), 612-620.

Le Roux, M., Geertsema, S., Jordaan, H. \& Prinsloo, D., 2017, 'Phonemic awareness of English second language learners', South African Journal of Communication Disorders 64(1), 1-9. https://doi.org/10.4102/sajcd.v64i1.164

Li, H., Zhang, J., Ehri, L., Chen, Y., Ruan, X. \& Dong, Q., 2016, 'The role of orthography in oral vocabulary learning in Chinese children', Reading and Writing 29(7), 1363-1381. https://doi.org/10.1007/s11145-016-9641-0

Li, M.Y., Braze, D., Kukona, A., Johns, C.L., Tabor, W., Van Dyke, J.A. et al., 2019, 'Individual differences in subphonemic sensitivity and phonological skills', Journal of Memory and Language 107, 195-215. https://doi.org/10.1016/j.jml.2019.03.008

Linnegar, K., Condy, J. \& McKinney, E., 2014, 'The impact of poor working memory skills on a grade 2 learner's written and oral literacy performace', Reading \& Writing - Journal of the Reading Association of South Africa 5(1), 1-6. https://doi. org/10.4102/rw.v5i1.37

Lynch, S., 2016, 'The effect of supplemental, explicit phonemic awareness intoduction on the reading achievement of kindergarten emerging readers and nonreaders', Culminating Experience Action Research Projects 18(1), 26-36.

Manten, A., Le Roux, M., Geertsema, S. \& Graham, M., 2020, 'An investigation into the early literacy skills of English second language learners in South Africa', Australasian JournalofEalryChildhood45(2),142-154.https://doi.org/10.1177/1836939120918504

Martin, N.A. \& Brownell, R., 2005, TAPS-3: Test of auditory processing skills, Academic Therapy Publications, Novato, CA.

Mehta, S., Ding, Y., Ness, M. \& Chen, E.C., 2018, 'Invented spelling, word stress, and syllable awareness in relation to reading difficulties in children', Journal of Psycholinguistic Research 47(3), 585-606. https://doi.org/10.1007/s10936-017-9547-2
Müller, B., Richter, T. \& Karageorgos, P., 2020, 'Syllable-based reading improvement: Effects on word reading and reading comprehension in grade 2 ', Learning and Instruction 66, 101304. https://doi.org/10.1016/j.learninstruc.2020.101304

Nevo, E., Vaknin-Nusbaum, V., Brande, S. \& Gambrell, L., 2020, 'Oral reading fluency, reading motivation and reading comprehension among second graders', Reading and Writing 33, 1945-1970. https://doi.org/10.1007/s11145-020-10025-5

Pfost, M., Blatter, K., Artelt, C., Stanat, P. \& Schneider, W., 2019, 'Effects of training phonological awareness on children's reading skills', Journal of Applied Developmental Psychology 65, 101067. https://doi.org/10.1016/j.appdev. 2019.101067

Pham, A. \& Hasson, R.M., 2014, 'Verbal and visuospatial working memory as predictors of children's reading ability', Archives of Clinical Neuropsychology 29(5), 467-477. https://doi.org/10.1093/arclin/acu024

Pham, G.T. \& Snow, C.E., 2020, 'Beginning to read in Vietnamese: Kindergarten precursor to first grade fluency and reading comprehension', Reading and Writing 34, 139-169. https://doi.org/10.1007/s11145-020-10066-w

Peng, P., Barnes, M., Wang, C., Wang, W., Li, S., Swanson, H.L. et al., 2018, 'A metaanalysis on the realtion between reading and working memory', Psychological Bulletin 144(1), 48-76. https://doi.org/10.1037/bul0000124

Pittas, E., 2018, 'Longitudinal contributions of phonemic awareness to reading Greek beyond estimation of verbal ability and morphological awareness', Reading \& Writing Quarterly 34(3), 218-232. https://doi.org/10.1080/10573569.2017.1390807

Rakhlin, N.V., Mourgues, C., Cardoso-Martins, C., Kornev, A.N. \& Grigorenko, E.L. 2019, 'Orthographic processing is a key predictor of reading fluency in good and poor readers in a transparent orthograph', Contemporary Educational Psychology poor readers in a transparent orthograph', Contemporary Educatich.

Read, K. \& Regan, M., 2018, 'The cat has a ... : Children's use of rhyme to guide sentence completion', Cognitive Development 47, 97-106. https://doi. org/10.1016/j.cogdev.2018.04.004

Robertson, C. \& Salter, W., 2018, The phonological awareness test 2: The statistics manual, LinguiSystems, East Moline, IL.

Saint-Aubin, J., Beaudry, O., Guitard, D., Pâquet, M. \& Guérard, K., 2020, 'The word length effect in backward recall: The role of response modality', Memory $28(5)$ 692-700. https://doi.org/10.1080/09658211.2020.1762896

Sarris, M., 2020, 'Learning to read in a shallow orthography: The effect of letter knowledge acquisition', International Journal of Early Years Education 1-18. https://doi.org/10.1080/09669760.2020.1814212

Schaars, M.M., Segers, E. \& Verhoeven, L., 2017, 'Predicting the integrated development of word reading and spelling in the early primary grades', Learning and Individual Differences 59, 127-140. https://doi.org/10.1016/j.lindif. 2017.09.006

Schaars, M.M., Segers, E. \& Verhoeven, L., 2019, 'Cognitive and linguistic precursors of early first and second language development', Learning and Individual Differences 72, 1-14. https://doi.org/10.1016/j.lindif.2019.03.008

Schaefer, M. \& Kotzé, J., 2019, 'Early reading skills related to grade 1 English second language literacy in rural South Africa schools', South African Journal of Childhood Education 9(1), 1-13. https://doi.org/10.4102/sajce.v9i1.644

Schmalz, X., Marinus, E. \& Castles, A., 2013, 'Phonological decoding or direct access? Regularity effects in lexical decisions of grade 3 and 4 children', The Quarterly Journal of Experimental Psychology 66(2), 338-346. https://doi.org/10.1080/174 70218.2012.711843

Stark, S., 2011, Dylexia, Prestige Art Press (Pty) Ltd., Johannesburg.

Steacy, L.M., Fuchs, D., Gilbert, J.K., Kearns, D.M., Elleman, A.M. \& Edwards, A.A. 2020, 'Sight word acquisition in first grade students at risk for reading disabilities: An item-level exploration of the number of exposures required for mastery' Annals of Dyslexia 70(2), 259-274. https://doi.org/10.1007/s11881-020-00198-7

Suggate, S., Reese, E., Lenhard, W. \& Schneider, W., 2014, 'The relative contributions of vocabulary: Decoding, and phonemic awareness to word reading in English versus German', Reading and Writing 27(8), 1395-1412. https://doi.org/10.1007/ s11145-014-9498-z

Suortti, O. \& Lipponen, L., 2016, 'Phonological awareness and emerging reading skills of two-to-five year old children', Ealry Child Development and Care 186(11) 1703-1721. https://doi.org/10.1080/03004430.2015.1126832

Swain, K.D., Leader-Janssen, E.M. \& Conley, P., 2013, 'Effects of repeated reading and listening passage preview on oral reading fluency', Reading Improvement 50(1), 105-111.

Tibi, S. \& Kirby, J.R., 2018, 'Investigating phonological awareness and naming speed as predictors of reading in Arabic', Scientific Studies of Reading 22(10), 70-84. https://doi.org/10.1080/10888438.2017.1340948

Toffalini, E., Marsura, M., Garcia, R.B. \& Cornoldi, C., 2019, 'A cross-modal working memory binding span deficit in reading disability', Journal of Learning Disabilities 52(2), 99-108. https://doi.org/10.1177/0022219418786691

Transvaal Education Department, 1987, One minute reading test, Transvaal Education Department, Pretoria, April 1987.

Vibulpatanavong, K. \& Evans, D., 2019, 'Phonological awareness and reading in Ta children', Reading and Writing 32(2), 467-491. https://doi.org/10.1007/s11145018-9867-0

Wang, S., Allen, R., Lee, J.R. \& Hsieh, C.E., 2015, 'Evaluating the development trajectory of the episodic buffer component of working memory and its relation to word recognition', Journal of Experimental Child Psychology 133, 16-28. https:// doi.org/10.1177/1747021817746929

Zuriyatiaslina, Y., Jawanees, A.H.N., Norhamimah, R., Juliana, M.N., Ngo, K.L. \& Salihah, A., 2018, 'Improving students' blending skill using onset-rime approach', Journal of Fundamental and Applied Sciences 10(2S), 847-857. 